\title{
Lyophilized Ethinylestradiol Nanosuspension: Fabrication, Characterization and Evaluation of in vitro Anticancer and Pharmacokinetic Study
}

\author{
T. A. POWAR AND A. A. HAJARE* \\ Department of Pharmaceutics, Bharati Vidyapeeth College of Pharmacy, Near Chitranagari, Kolhapur-416 013 , India
}

Powar and Hajare: Lyophilized Nanosuspension for Bioavailability Enhancement

\begin{abstract}
The present investigation was aimed to fabricate lyophilized nanosuspension of poorly soluble ethinylestradiol in order to enhance oral bioavailability and stability. The top-down high-pressure homogenization technique was used to formulate the desired dosage form. The formulations were characterized and optimized for compatibility, crystallographic investigation, surface topography, drug release, in vitro apoptosis and cytotoxicity and in vivo pharmacokinetic investigations. The mean particle size and zeta potential of the optimized lyophilized ethinylestradiol nanosuspension were $220 \pm 0.37 \mathrm{~nm}$ and $-19.3 \pm 6.73 \mathrm{mV}$, respectively. The surface topographical studies showed needle-shaped particles from bar shape upon nanonization by high-pressure homogenization technique. Differential scanning calorimetry and $\mathrm{X}$-ray powder diffraction studies confirmed the crystalline nature of ethynylestradiol after nanonization. The dissolution rate of ethinylestradiol nanosuspension was improved as compared to ethinylestradiol powder. In vitro cytotoxicity of ethinylestradiol nanosuspension on MCF-7 cell line showed more than $80 \%$ inhibition of viability of cells relative to that produced by ethinylestradiol aqueous dispersion. Noteworthy, apoptotic cells treated with ethinylestradiol nanosuspension showed shrinkage, followed by fragmentation and cell death. Significantly, ethinylestradiol nanosuspension enhanced $C_{\max }$ and $\mathrm{AUC}_{0-\mathrm{t}}$ by 1.5 -fold and 1.7 -fold compared to that of the aqueous solution. The relative bioavailability of ethinylestradiol was enhanced 2-fold and high concentrations were found to be distributed to liver, spleen and stomach. Thus lyophilized nanosuspension could be a better approach to enhance solubility, oral bioavailability and stability of ethinylestradiol in pharmaceutical formulations.
\end{abstract}

Key words: Ethinyl estradiol, lyophilized nanosuspension, stability, cytotoxicity, apoptosis, bioavailability

Ethinylestradiol (EE), (17a)-19-norpregna-1,3,5-(10) trien-20-yne-3,17-diol is an estrogenic component, which is widely used in hormone replacement therapy and as an oral contraceptive. EE is mostly found in all birth control pills in combination and this is a special oestrogen used as an oral contraceptive with increased demand $^{[1-3]}$. It is also known for its effectiveness to treat breast cancer, prostate cancer ${ }^{[4-9]}$, as high-dose EE is an effective first-line treatment and also used for treatment endocrine resistance to aromatase inhibitors and tamoxifen ${ }^{[10]}$. EE is yellow to white crystalline powder, insoluble in water but soluble in ether, ethanol, acetone, chloroform and dioxane. It is also found to be soluble in dilute alkaline solutions and vegetable oils. It is available in small doses alone or with a combination ${ }^{[11]}$. However, EE has a poor aqueous solubility, which is the biggest hurdle in the clinic application for cancer

*Address for correspondence

E-mail: ashok.hajare@bharatividyapeeth.edu

January-February 2020

Indian Journal of Pharmaceutical Sciences the identical terms treatment. Lower solubility leads to complications in drug delivery like unpredictable absorption and thus unacceptable oral bioavailability. Due to extensive first-pass hepatic metabolism after oral administration, EE has $40 \%$ of systemic bioavailability due to its initial conjugation within the gut wall ${ }^{[11]}$. Therefore, solubility enhancement of EE should be considered first for its development.

Various traditional approaches are used to enhance the solubility of poorly soluble drugs, which include micronization, use of cyclodextrin and co-solvents ${ }^{[11]}$.

This is an open access article distributed under the terms of the Creative Commons Attribution-NonCommercial-ShareAlike 3.0 License, which allows others to remix, tweak, and build upon the work non-commercially, as long as the author is credited and the new creations are licensed under

Accepted 16 November 2019 Revised 24 August 2019 Received 26 April 2019 Indian J Pharm Sci 2020;82(1):54-65 
But unfortunately, the problem of bioavailability remains unsolved in many cases. In the case of micronization, sufficient surface area is not produced in order to enhance the dissolution velocity of poorly water-soluble drugs. Thus, pharmaceutical industry focus shifted to nanonization (formulation of nanosuspension, NS) from micronization ${ }^{[12]}$.

In scientific research, nanomedicines attained prominence due to application as these are advantageous due to greater surface area owing to their particle size ${ }^{[13,14]}$. In the last few decades, many new drugs failed to reach the clinic due to issues related to solubility, dissolution and bioavailability ${ }^{[15,16]}$. This might be due to a lack of dose proportionality, uncertain drug absorption, poor dissolution and interintra subject variability ${ }^{[17]}$. Fabrication of practical water-insoluble or very slightly soluble drugs to NS appeared advantageous to circumvent previously mentioned problems ${ }^{[18]}$. NS is a submicron colloidal suspension, which consists of dispersed drug particles in water along with polymer as stabilizer or surfactant through top-down or bottom-up techniques ${ }^{[19,20]}$. NS has emerged as a potential solubility enhancement technique more recently ${ }^{[21]}$, in which the poorlysoluble drugs are suspended in dispersion without any matrix material. NS of various drugs are prepared with a small amount of stabilizer below critical micelle concentration to stabilize the formulation. Generally, most nanoparticle formulations are developed using a larger concentration of excipients but it is not the case with NS, as most part is the drug. Due to the use of only a small concentration of stabilizers in formulation of NS, toxicity issues are negligible while offering better physical and chemical stability with ease of scale-up as compared to amorphous form. NS enhances the solubility of poorly soluble drugs in aqueous as well as non-aqueous media. Increased solubility leads to an increase in the quantity of drug absorbed to attain maximum plasma level at a faster rate. The reduced particle size makes these drugs suitable for intravenous administration without blocking blood capillaries. This technique is applicable to molecules that have poor permeability, poor solubility, or both such as the BCS class II and IV drugs ${ }^{[22-25]}$. For developing a NS product, various methods have been reported to be employed that include top-down techniques such as media milling, high-pressure homogenization (HPH), sonication and bottom-up technique of nanoprecipitation. To enhance the physical stability of NS, numerous solidification techniques have been used, which include lyophilization, spray drying, rotary evaporation and many more based on the physical properties of drugs and characteristics of the final formulation ${ }^{[1,26-28]}$. Out of all techniques listed above, lyophilization is predominately used for solidification of NS, as it offers several merits which include suitability for drying of thermolabile drugs, easy reconstitution of the formulation before use, enhanced storage stability and ability to produce highvalue products without excessive damage ${ }^{[21]}$. Thus the development of EE in lyophilized NS form could be a useful tool to tackle the aforesaid problems.

In present investigation, an attempt was made to prepare NS of EE using a top-down technique such as HPH, along with Tween 80 as a stabilizer and soya lecithin as a polymer to inhibit particle aggregation with an objective to enhance the bioavailability and stability of EE as a lyophilized NS. The EENS prepared was lyophilised and the zeta potential, particle size, polydispersity index (PDI), surface topography, dissolution efficiency, in vitro cytotoxicity, in vivo pharmacokinetics and biodistribution and the stability of the lyophilised product were studied.

\section{MATERIALS AND METHODS}

EE and methotrexate were gifted by Cipla Ltd. Goa, India. Tween 80 and mannitol was procured from Merck Specialities Pvt. Ltd. Mumbai, India. Soya lecithin (Phospholipon $^{\circledR} 90 \mathrm{H}$ ) was gifted by Lipoid $\mathrm{GmbH}$, Germany. high performance liquid chromatography (HPLC) grade methanol was procured from Thermo Fisher Scientific Pvt., Ltd., Mumbai, India. Doubledistilled water was prepared in the laboratory and all other reagents used in the study were of analytical grade.

\section{Formulation and lyophilization of EENS:}

EENS were fabricated using HPH (Panda Plus 2000, GEA Niro Soavi, Germany). To prevent blocking of the homogenizer valve, the coarse powder ofEE $(0.5 \mathrm{mg} / \mathrm{ml})$ was first dispersed in the aqueous stabilizer solution of Tween $80(0.15 \% \mathrm{v} / \mathrm{v})$ and soya lecithin $(30 \mathrm{mg})$ using a digital homogenizer at $3000 \mathrm{rpm}$ for $1 \mathrm{~h}$ to form the primary NS. The primary NS was further processed through an HPH with three homogenization cycles at 250, 700 and 1200 bars, followed by maximum cycles at 1500 bar. By varying the number of homogenization cycles and keeping process temperature constant at $25^{\circ}$, different particle size EENS were obtained ${ }^{[29]}$. Liquid EENS formulations were processed for lyophilization using laboratory freeze dryer (Freezone12, Labconco, MO, USA) with mannitol ( $6 \% \mathrm{w} / \mathrm{w})$ as a cryoprotectant. 
The formulations were pre-freeze at $-30^{\circ}$ for $12 \mathrm{~h}$. The primary drying was performed at $-53^{\circ}$ and $0.016 \mathrm{mBar}$ for $24 \mathrm{~h}$. The secondary drying was performed at $10^{\circ}$ for $8 \mathrm{~h}$ and was followed by drying at $25^{\circ}$ for $4 \mathrm{~h}$ with a gradual increase in temperature at $1 \% \mathrm{~min}$. Finally, the temperature of the cold trap was maintained at $-53^{\circ}$ until completion of the drying process. The resultant powder of EENS was further used for subsequent evaluation studies ${ }^{[29-31]}$.

\section{Particle size, PDI and particle charge of lyophilized EENS:}

Particle size, zeta potential, and PDI of the prepared EENS was measured using a Zetasizer 300 HAS (Malvern Instruments, Malvern, UK). Prior to size determination, lyophilized NS was redispersed in distilled water. Data obtained were mean average values of 3 independent samples that are prepared under the same formulation conditions ${ }^{[30,32]}$.

\section{Scanning electron microscopy (SEM):}

The SEM was used to study the surface morphology of EENSs which examines sphericity, discreteness and surface properties of NPs. SEM studies were performed using an SEM (Jeol JSM-6360, Japan) at $20 \mathrm{kV}$ accelerating voltage and high vacuum. Before analysis, lyophilized EENS were first placed on two-sided carbon tape and then, sputtered with gold-palladium alloy up to $3-5 \mathrm{~nm}$ of thickness ${ }^{[30,33]}$.

\section{Inverted phase contrast microscopy:}

The microstructures of EENSs were characterized using inverted phase-contrast microscopy. Formulations were first diluted with distilled water $(1: 10)$ and placed on a glass slide to prepare a thin layer. The excess of the sample was wiped-off using filter paper. It was allowed to dry for half an hour at room temperature (RT) and then observed under the microscope.

\section{X-ray powder diffraction (XRPD) analysis:}

The XRPD spectra of the EE, physical mixture (PM) and optimized EENS were obtained using an X-ray diffractometer (Philips Analytical XRD, PW 3710) with $\mathrm{Cu}-\mathrm{K} \alpha$ radiation $(1.54 \AA)$, at $40 \mathrm{kV}, 40 \mathrm{~mA}$ by passing through a nickel filter. The samples were analyzed in the $2 \theta$ angle range of 5 to $80^{\circ}$. The range and the chart speed were $5 \times 10^{3} \mathrm{CPS}$ and $10 \mathrm{~mm} /{ }^{\circ} 2 \theta$, respectively ${ }^{[31]}$.

\section{Differential scanning calorimetry (DSC) analysis:}

The thermal behavior of EE, PM of EE with excipients and optimized EENS were studied using a Perkin Elmer 4000e module controlled by PYRIS Version-11.1.0.0488 (PerkinElmer, Inc., USA). For each analysis, before heating under nitrogen purging (20 $\mathrm{ml} / \mathrm{min})$, the samples ( $1 \mathrm{mg}$ ) were placed in sealed aluminium pans, and scanned at a scanning rate of $10^{\circ} / \mathrm{min}$, for a temperature range of $30^{\circ}$ to $350^{\circ[31]}$.

\section{In vitro dissolution study:}

Dissolution studies on EE powder and optimized EENS were carried out using USP type-II apparatus. Weighed quantities of samples were transferred into the dissolution apparatus (ElectroLab TDT-08 L, India) containing $900 \mathrm{ml}$ of simulated gastric fluid (SGF) as a medium with $\mathrm{pH} 1.2$. The shaft speed was set to $50 \mathrm{rpm}$ at medium temperature $37 \pm 0.5^{\circ}$. Samples ( $5 \mathrm{ml}$ each) were withdrawn at $10,20,30,40,50$ and 60 min time intervals and the fresh buffer was added to maintain the sink conditions. The samples were collected and filtered using Whatman filter paper $(0.25 \mu \mathrm{m}$, Whatman Inc., USA) and analyzed using UV spectrophotometer at $280 \mathrm{~nm}^{[33,34]}$.

\section{In vitro cytotoxicity study on MCF-7 cells:}

Cytotoxicity of optimized EENS and EE aqueous dispersion (EEAQD) was studied on human MCF-7 breast cancer cell line. Cell line was cultured and maintained at $37^{\circ}$ in a humidified $5 \% \mathrm{CO}_{2}$ incubator (NBS Eppendorf, Germany). In each well of a 96 well microliter plate, about $50 \mu 11 \times 10^{5}$ cells $/ \mathrm{ml}$ cell suspension was seeded and final volume was made to $150 \mu \mathrm{l}$ by adding Dulbecco's modified Eagle medium (DMEM) media. Dilutions of EENS were made in DMEM media and about $100 \mu$ of different concentrations of EENS and EEAQD (62.5, 125, $250,500,1000 \mu \mathrm{g} / \mathrm{ml}$ ) were added and incubated for $48 \mathrm{~h}$ in presence of $5 \% \mathrm{CO}_{2}$ at $37^{\circ}$ in an incubator. After $48 \mathrm{~h}, 20 \mu \mathrm{l}$ 3-(4,5-dimethylthiazol-2-yl)-2,5diphenyltetrazolium bromide (MTT) reagent $(5 \mathrm{mg} / \mathrm{ml})$ was added to the wells and the plates were kept for $4 \mathrm{~h}$ to incubate in dark place at RT. The plates were covered with aluminium foil as MTT reagent is photosensitive. Without disturbing the precipitated formazan crystals, the supernatant was removed carefully and $100 \mu 1$ dimethyl sulfoxide was added to dissolve these crystals. The optical density (OD) was measured using the ELISA microplate reader at $492 \mathrm{~nm}$. Baseline was obtained using culture medium and the wells with only cells were used as control. With an assessment of colorimetry and spectrophotometry, the in vitro growth inhibition effect of EENS and EEAQD was measured 
by the conversion of MTT into formazan blue by living cells. The study was performed in triplicate. The generated dose-response curve was used to determine the $\mathrm{IC}_{50}$ of test samples required to inhibit the growth of cells by $50 \%$. The $\%$ growth inhibition was calculated using the following Eqn. 1, growth inhibition (\%) $=1-($ mean OD of a test compound $) /($ mean OD at untreated cells) $\times 100$.

\section{Direct microscopy:}

The entire plate was observed under an inverted phasecontrast tissue culture microscope (Olympus CKX41 with Optika Pro5 CCD camera) after $48 \mathrm{~h}$ of treatment with EENS and EEAQD. Changes in cell morphology such as shrinking or rounding of cells, granulation and vacuolization in the cytoplasm were considered as indicators of cytotoxicity.

\section{Fluorescent microscopic determination of apoptosis using double staining method:}

The MCF-7 cells were washed using cold phosphate buffer saline (PBS) solution after treating them with different concentrations of EENS and EEAQD (13.23, $26.45 \mathrm{LD}_{50}, 52.91 \mu \mathrm{g} / \mathrm{ml}$ ) for $48 \mathrm{~h}$, followed by staining with the mixture of acridine orange (AO; $100 \mu \mathrm{g} / \mathrm{ml}$ ) and ethidium bromide (EB; $100 \mu \mathrm{g} / \mathrm{ml}$ ) for $10 \mathrm{~min}$ at RT. The stained cells were washed twice with PBS solution and observed under a fluorescent microscope (Olympus CKX41 with Optika Pro5 camera) using a blue filter ${ }^{[35]}$. Based on staining reactions, the cells were categorized as normal green nucleus (living cells), bright green nucleus with fragmented or condensed chromatin (early apoptotic), orange-stained nuclei with fragmentation or chromatin condensation (late apoptotic) and uniformly orange-stained cell nuclei (necrotic cells).

\section{Pharmacokinetic and biodistribution study in Sprague Dawley rats:}

Pharmacokinetic and biodistribution studies were performed using Sprague Dawley rats, weighing 200$220 \mathrm{~g}$, purchased from Global Bioresearch Solutions Pvt. Ltd., Pune. The Institutional Animal Ethics Committee of Bharati Vidyapeeth College of Pharmacy, Kolhapur, Maharashtra, India has approved the study protocol (BVCPK/CPCSEA/IAEC/01/14/2017-2020). Prior to the experiment, rats were kept on overnight fast with access to water ad libitum. These rats were randomly divided into 3 groups $(n=3)$. Group I was given optimized EENS (test group), group II was treated with EEAQD (standard group), whereas group III was given normal saline solution (control group).
On the day of the experiment, samples and dosing $(0.5 \mathrm{mg} / \mathrm{kg})$ of optimized EENS and EEAQD were prepared freshly and administered orally to rats using a feeding cannula. Under mild anesthesia, blood samples $(0.5 \mathrm{ml})$ were collected at $0,2,3,4,6,12,24,36$ and $48 \mathrm{~h}$ from the retro-orbital vein and were transferred into a tube containing EDTA. Immediately blood samples were centrifuged at $3000 \mathrm{rpm}$ for $10 \mathrm{~min}$ at $4^{\circ}$ to separate plasma and were stored at $-20^{\circ}$ until analysis.

The animals were sacrificed $(n=3)$ by cervical dislocation. EE levels in vital organs was measured $72 \mathrm{~h}$ after dose administration. Samples of liver, spleen, heart, brain, stomach, lungs, and kidney were homogenized quickly followed by centrifugation and the clear supernatants obtained were stored at $-20^{\circ}$ till analysis. The blood plasma and tissue samples were mixed with $20 \mu$ internal standard solution (methotrexate, $5 \mu \mathrm{g} / \mathrm{ml}$ ). Deproteinization was done by adding $100 \mu \mathrm{l}$ acetonitrile to $50 \mu \mathrm{l}$ plasma sample and $300 \mu \mathrm{l}$ acetonitrile to $200 \mu \mathrm{l}$ of clear tissue homogenates followed by centrifugation at $6000 \mathrm{rpm}$ for $15 \mathrm{~min}$ at $4^{\circ}$. Transparent supernatant obtained was filtered using a $0.20 \mu \mathrm{m}$ syringe filter and injected into the HPLC system for determining EE content in plasma and tissue samples ${ }^{[34,36]}$.

\section{HPLC analysis:}

EE content was analyzed using a reverse phase-HPLC system with a UV detector and with a pump (Model Jasco PU-2080, intelligent HPLC pump). A reverse phase C18 column $(150 \times 4.6 \mathrm{~mm}$, pore size $5 \mu \mathrm{m}$, Phenomenex) was used to achieve chromatographic separation. The mobile phase optimized was 70:30 v/v mixture of water and acetonitrile. The separation was carried out under an isocratic condition with a constant flow rate of $1.0 \mathrm{ml} / \mathrm{min}$, with $20 \mu \mathrm{l}$ injection volume, at a column temperature of $25^{\circ}$, and wavelength of $280 \mathrm{~nm}$. The calibration curve for EE in plasma was linear within the concentration range $0.5-10 \mu \mathrm{g} / \mathrm{ml}$ with correlation coefficient $\mathrm{R}^{2}=0.9932$, with methotrexate as an internal standard. The experimental data are expressed as mean $\pm \mathrm{SD}^{[37]}$.

\section{Pharmacokinetic analysis:}

The pharmacokinetic analysis of the plasma concentration-time profile was carried out employing the non-compartmental model using Microsoft Excel (Microsoft office 2016). The PK parameters were directly obtained from plasma concentration data, 
including area under the plasma concentration time curves $\left(\mathrm{AUC}_{0-\mathrm{t}}\right)$, maximum plasma concentration $\left(\mathrm{C}_{\max }\right)$, time to reach maximum plasma concentration $\left(\mathrm{T}_{\max }\right)$, elimination half-life $\left(t_{1 / 2}\right)$, mean residence time (MRT), elimination rate constant $\left(\mathrm{K}_{\mathrm{el}}\right)$, volume of distribution (VD), clearance $(\mathrm{Cl})$, and relative bioavailability $\left(\mathrm{F}_{\text {rel }}\right)$. $\mathrm{F}_{\text {rel }}$ of lyophilized EENS after oral administration was computed according to the following formula with the EEAQD as a reference, Eqn. 2, $\mathrm{F}_{\text {rel }}=(\mathrm{AUC}$ test $) /$ (AUC reference) $\times 100$. All data were expressed as mean $\pm \mathrm{SD}^{[30]}$.

\section{Stability studies:}

Stability studies of optimized lyophilized EENS and liquid EENS were performed as per ICH Q1A (R2) guidelines. The formulations were wrapped in aluminum foils and stored at $4^{\circ}$ (refrigerator), RT in shadow and at $40 \pm 2^{\circ}$ temperature and $75 \pm 5 \%$ relative humidity (in a stability chamber) for $6 \mathrm{mo}$ and at specific time interval drug content and particle size of the stored samples were evaluated to obtain chemical and physical stability ${ }^{[38]}$.

\section{Statistical analysis:}

The data generated was analyzed using multilinear regression analysis, ANOVA and lack-of-fit tests. To test the statistical significance, wherever applicable, student's t-test was used and expressed as mean $\pm \mathrm{SD}$ $(n=3)$.

\section{RESULTS AND DISCUSSION}

EE is a coarse micronized powder with fine white texture, poor flow properties and aqueous solubility. The coarse EE particles bear average particle size of 5-7 $\mu \mathrm{m}$, with a PDI of 1.38 indicating broad size distribution. The freshly prepared NS was lyophilized to enhance its stability. The lyophilized EENS powder was smooth in appearance with a particle size of $220 \pm 0.37 \mathrm{~nm}$ (fig. 1A), which was easily re-dispersed

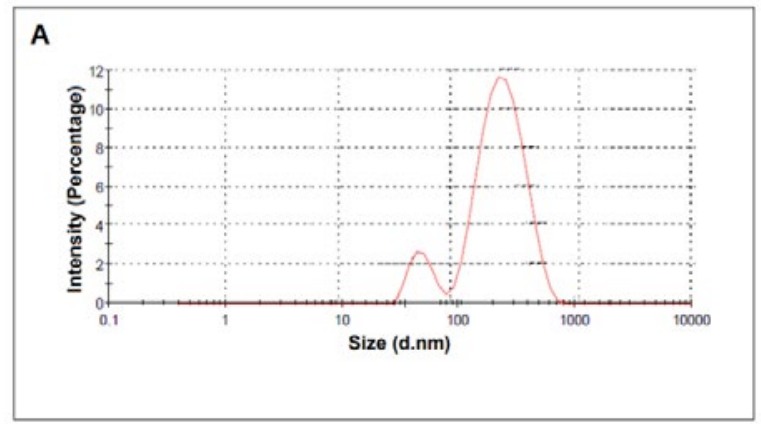

Fig. 1: Average particle size and zeta potential

Graphs showing (A) average particle size and (B) zeta potential upon gentle shaking. It was reported that narrow and uniform particle size distribution favours dissolution enhancement, boosts intestinal absorption and improves oral bioavailability ${ }^{[36]}$. Optimized EENS showed PDI value equal to $0.22 \pm 0.15$ indicating narrow distribution of particles and thus better stability of NS.

Another important significant index is zeta potential, which directly affects the stability of the dispersion system, as it reflects steric or electrostatic barriers preventing aggregation and agglomeration of nanoparticles. When drug particles possess very low zeta potential value to provide sufficient steric or electric repulsion between each other, aggregation of particles is likely to occur. Generally, for electrostatically stabilized systems, maximum $-30 \mathrm{mV}$ of zeta potential or sterically stabilized formulation system at least $-20 \mathrm{mV}$ was sufficient for physical stabilization of NS (fig. 1B). The zeta potential of reconstituted EENS was $-19.3 \pm 6.73 \mathrm{mV}$ indicating good physical stability of the optimized $\mathrm{NS}^{[36]}$.

The coarse EE particles under SEM exhibited an average particle size of 5-7 $\mu \mathrm{m}$ with a broad size distribution (fig. 2A). The SEM (fig. 2B) of optimized lyophilized EENS showed that particles were discrete with slight agglomeration that could be assigned to the presence of stabilizer at particle water interface. These had a porous surface and found to be slightly elongated and needle shaped. These pores might have been developed due to evaporation of the solvent from the surface of EENS during lyophilization. Thus SEM pictures confirmed that the larger scaly particles of EE were successfully converted to nearly elongated, smaller sized nanoparticles with a smoother surface on size reduction. The particle size of EENS increased after lyophilization but were still smaller than that of $\mathrm{EE}^{[33]}$.

The stability and dissolution behaviour of compounds is influenced by crystalline state. During the HPH

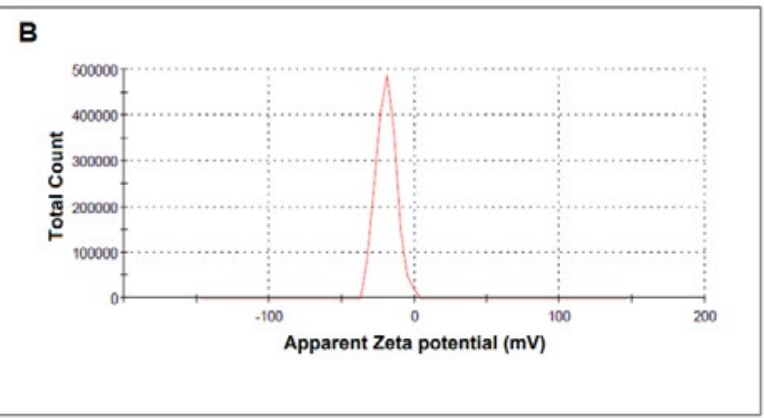




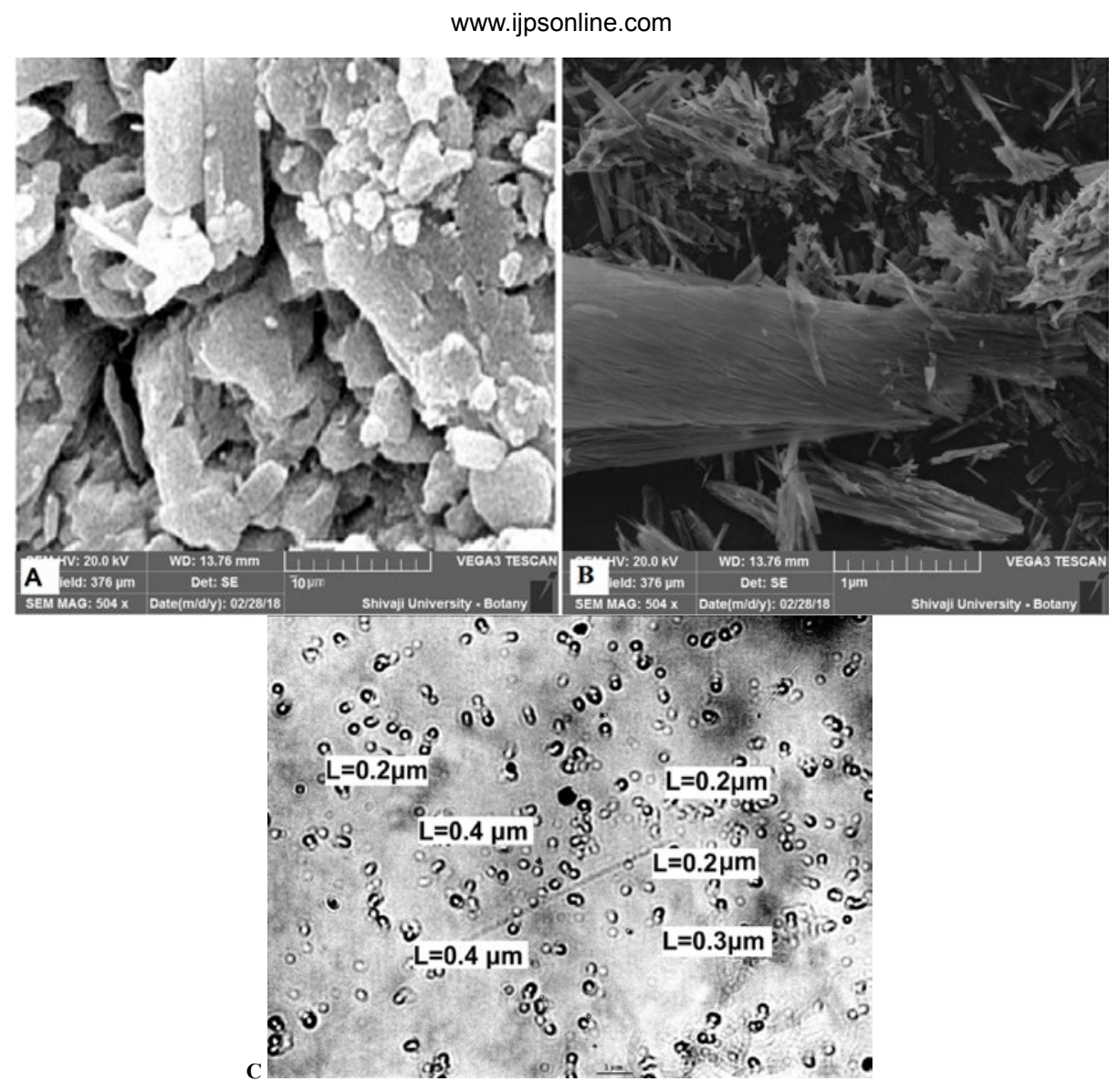

Fig. 2: Photomicrographs of SEM and inverted phase microscopic images of EE and EENS

Scanning electron microscope (SEM) photomicrographs of A. pure EE, B optimised ethinylestradiol nanosuspension (EENS) and C. inverted phase microscopic images of EENS

process, a high-energy input was generated due to high power density in the piston-gap of the homogenizer. This led to an increase in the amorphous portion or complete amorphization of EE. The extent of development of amorphous nature depended on the applied power density as well as the physical hardness and chemical nature of a drug. Thermal analysis of EE, PM, optimized EENS and mannitol was performed to study the differences among these and the results were presented as fig. 3A. Coarse EE powder showed a sharp distinct endothermic peak at $184.41^{\circ}$, which corresponded to the intrinsic melting point of EE, while DSC of PM showed two distinct melting endothermic peaks at 166.85 and $178.63^{\circ}$, whereas EENS powder recorded sharp melting endotherm at $168.83^{\circ}$. Mannitol showed a sharp endothermic peak at $168.74^{\circ}$ indicating its high crystallinity. The characteristic peak of EE disappeared in the thermogram of optimized EENS, while the peak in the thermogram of PM was with decreased intensity. These changes were as predicted due to the diluting effect of excipients on EE, especially at higher concentrations of mannitol that had covered the melting peak of EE. Thus, it can be concluded that the crystallinity of EE decreased because of its encapsulation by stabilizers. Data obtained from DSC failed to explain factual changes that occurred in drug crystals during processing ${ }^{[39]}$.

The XRPD patterns of powder EE, PM and optimized EENS are presented in fig. 3B. Five sharp characteristic diffraction peaks exhibited by EE at 13.54, 15.36, 16.5, 18 and $19.42^{\circ} 2 \theta$ and several short peaks between 10.66 and $32.36^{\circ} 2 \theta$ indicated highly crystalline nature. PM demonstrated two reflections at 20.52 and $21.66^{\circ} 2 \theta$ with lower intensity compared to EE and EENS. It showed additional peaks similar to that of parent crystalline EE. The diffractogram of EENS showed 5 diffraction lines but with lower intensity as compared to $\mathrm{EE}$ at $13.52,17.74,19.86,20.14$ and $21.22^{\circ} 2 \theta$ with additional peaks of mannitol. In the XRPD spectrum of EENS, characteristic peaks were of lower intensity than EE without any qualitative variations and this could be due to the diluting effect of addition of mannitol. This pattern revealed that the crystalline state of EE and optimized EENS were the same, indicating the HPH process and the lyophilization process did not induce any crystal polymorphic transition in EE. In fact, amorphous forms are physically unstable compared to crystalline forms. Thus, during the entire 


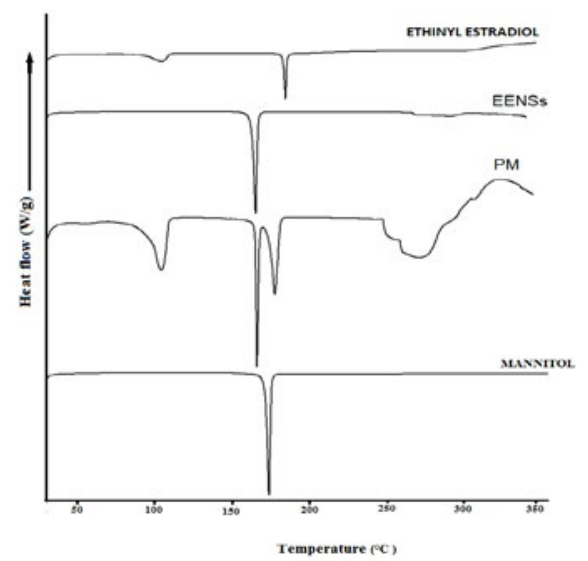

$\mathbf{A}$

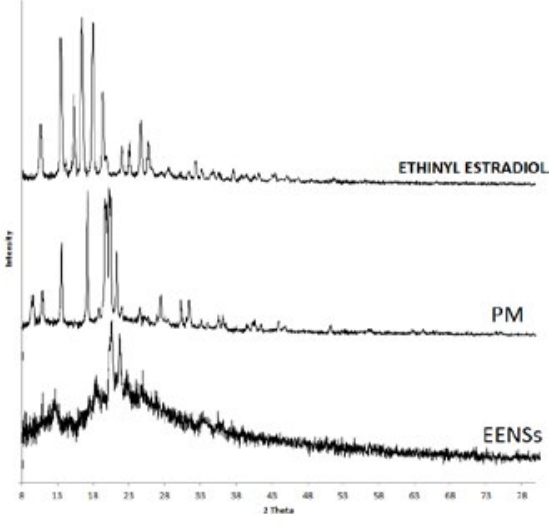

Fig. 3: (A) DSC thermogram and (B) XRPD spectra

storage period, the optimized EENS was assumed to be physicochemically stable. However, for long-term stability, maintenance of the original crystal structure is beneficial due to its lower state of energy. Moreover, the same induced properties and results were confirmed by previously reported studies ${ }^{[36]}$.

The dissolution behaviour of EE coarse powder and lyophilized EENS in SGF pH 1.2 is shown in fig. 4. The dissolution rates of EE and EENS in SGF were 26.199 and $95.101 \%$, respectively. EE release from EENS followed the Higuchi matrix model $\left(\mathrm{R}^{2}=0.9982\right)$. Hence EE particles might have dispersed in a uniform matrix and the drug released by diffusion process based on Fick's law. The EENS showed a dramatic increase in dissolution rate as compared to EE coarse powder. Moreover, EENS displayed more than $60 \%$ increase in dissolution rate compared to EE coarse powder (15\%) within 60 min indicating a distinctly superior dissolution profile of EENS relative to EE. This enhancement in dissolution of EE could be attributed to the reduction in particle size, especially in nanometre range with an effective increase in surface area that increased dissolution. This phenomenon is better explained by Noyes-Whitney Eqn. 3, dC/dt $=\mathrm{DS}-\left(\mathrm{C}_{\mathrm{s}}-\mathrm{C}_{\mathrm{t}}\right) / \mathrm{h}$, where $\mathrm{h}$ denotes thickness of the dissolution boundary layer, $\mathrm{D}$ is the diffusion coefficient of the solute, $\mathrm{C}_{\mathrm{s}}$ is saturation solubility, $\mathrm{S}$ represents the surface area, $\mathrm{dC} / \mathrm{dt}$ represents the dissolution rate and $\mathrm{C}_{\mathrm{t}}$ is the bulk concentration. As the particle size of EENS was smaller than that of EE, these possessed much larger surface area and hence a faster dissolution rate.

Besides particle size, particle shape also affects the dissolution of drugs ${ }^{[36]}$. Particles that are irregular, flaky and long exhibit a higher hydrodynamic thickness at the boundary layer. Thus, the value of $h$ would be increased with a decrease in dissolution rate. The SEM image of EE showed rod-shaped particles in different sizes. Thus it can be concluded that enhancement in dissolution rate was due to particle size reduction than that of shape alteration.

In order to study the effect of EE on cell proliferation, MCF-7 breast cancer cells were cultured with EENS and EEAQD. The cell inhibition ratio was evaluated using the MTT assay. The inhibition of MCF-7 cell growth by EENS was observed to be dose and timedependent. However, significant inhibition of MCF-7 cell proliferation was observed when treated with EENS at $62.5 \mu \mathrm{g} / \mathrm{ml}$ concentration. The EENS-treated cells showed a significant increase in growth inhibition rate compared to EEAQD-treated cells, fig. 5. These findings appear to due to the ability of EENS to infiltrate into cells either by endocytosis or phagocytosis or by increasing contact time and area between EE and the cells. The smaller size EENS initiated its adhesion to MCF-7 cells. The increased solubility and dissolution rates in EENS helped to attain sufficient concentration of EE around the cells. Thus, the EENS was found to be more cytotoxic to MCF-7 cells than free EE. The $\mathrm{IC}_{50}$ of EENS and EEAQD were 37.43 and $130.2 \mu \mathrm{g} /$ $\mathrm{ml}$, respectively. The $\mathrm{IC}_{50}$ of EENS was lower than EEAQD at $48 \mathrm{~h}$ incubation time. Engblom et al. ${ }^{[40,41]}$ and

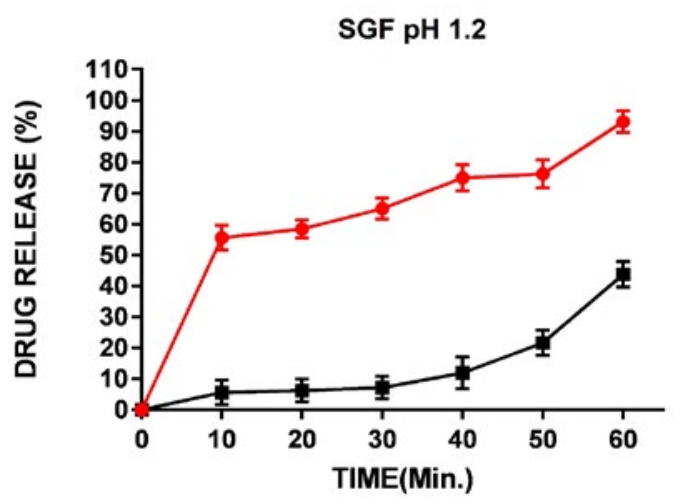

Fig. 4: Dissolution profiles of EENS and EE in simulated gastric fluid

Dissolution profiles of optimized ethinylestradiol nanosuspension (EENS) and the pure ethinylestradiol (EE) in simulated gastric fluid. (-•-) EENS, (一匹-) EE 
Wong et al. ${ }^{[42]}$ reported that excipients used in EENS do not exert any significant effect on the growth of MCF-7 cells. Thus, cytotoxicity study provided additional information that EE exerted anticancer activity, although EE was mostly used as an oral contraceptive agent.

EENS-induced morphological changes in MCF-7 cells are shown in fig. 6 . The morphological changes noticeable in cells included membrane blabbing, nuclear fragmentation and shrinkage of cells after exposure to EENS and EEAQD for $48 \mathrm{~h}$. More obvious changes were observed in EENS-treated cells which were absent in untreated control cells ${ }^{[42]}$.

Apoptosis study using double staining method revealed the ability of EE to induce apoptosis. A green color nucleus is seen, fig. 7A, which is an indication of

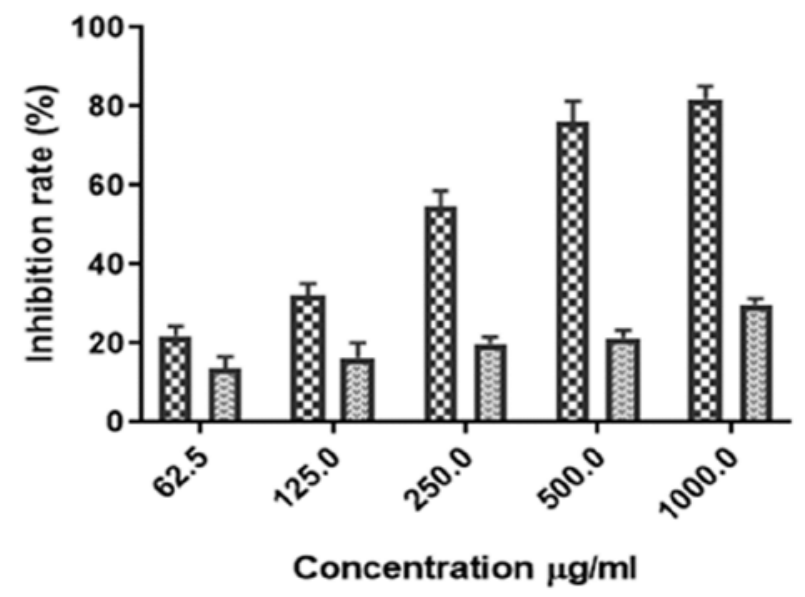

Fig. 5: Cytotoxicity of EENS and EEAQD

Cytotoxicity of ethinylestradiol nanosuspension (EENS) and ethinylestradiol aqueous dispersion (EEAQD) after $48 \mathrm{~h}$ of incubation (G) EENS, ([I) EEAQD; $n=3$, mean \pm standard deviation living cells in the control group, which were untreated. The decreasing ratio of living cells with increasing concentration of EEAQD and EENS could be observed in fig. 7B and C. At $12.5 \mu \mathrm{g} / \mathrm{ml}$ concentration, both EEAQD- and EENS-treated cells were uniformly orange-stained with fluorescent nuclei but to a lesser extent in EEAQD-treated cells compared to EENStreated cells, which indicated necrosis of cells followed by death. The morphological changes that occurred in apoptotic cells exposed to EENS included shrinkage of cells, followed by fragmentation and shape alteration. Such morphological changes were observed to a greater extent in cells treated with EENS as compared to those treated with EEAQD. Thus, the reduction of viable MCF-7 cells indicated an increase in the ratio of apoptotic cells. The apoptosis observed could be due to EE-induced physiological changes that included increased gene expression ${ }^{[35]}$.

In order to investigate the oral bioavailability enhancement effect of $\mathrm{EE}$, in vivo $\mathrm{PK}$ studies of EENS and EEAQD were carried out in rats and results obtained were compared with each other. The mean EE concentration-time profile in the rat plasma is shown in fig. 8A, after oral administration of a single dose of $0.5 \mathrm{mg} / \mathrm{kg}$ of EE from EENSs and EEAQD and their PK parameters obtained are listed in Table 1.

Following the oral administration of EENS and EEAQD, the plasma concentration of EE from EENS in rats reached a significantly higher level than that of EEAQD at every time interval. The EENS exhibited higher $\mathrm{C}_{\max }$, which indicated greater $\mathrm{EE}$ absorption. The $\mathrm{C}_{\max }$ of EENS was increased by 2 fold. The lower $\mathrm{C}_{\max }$ of EEAQD might be due to rapid distribution and metabolism of EE. The coating of soya lecithin helped

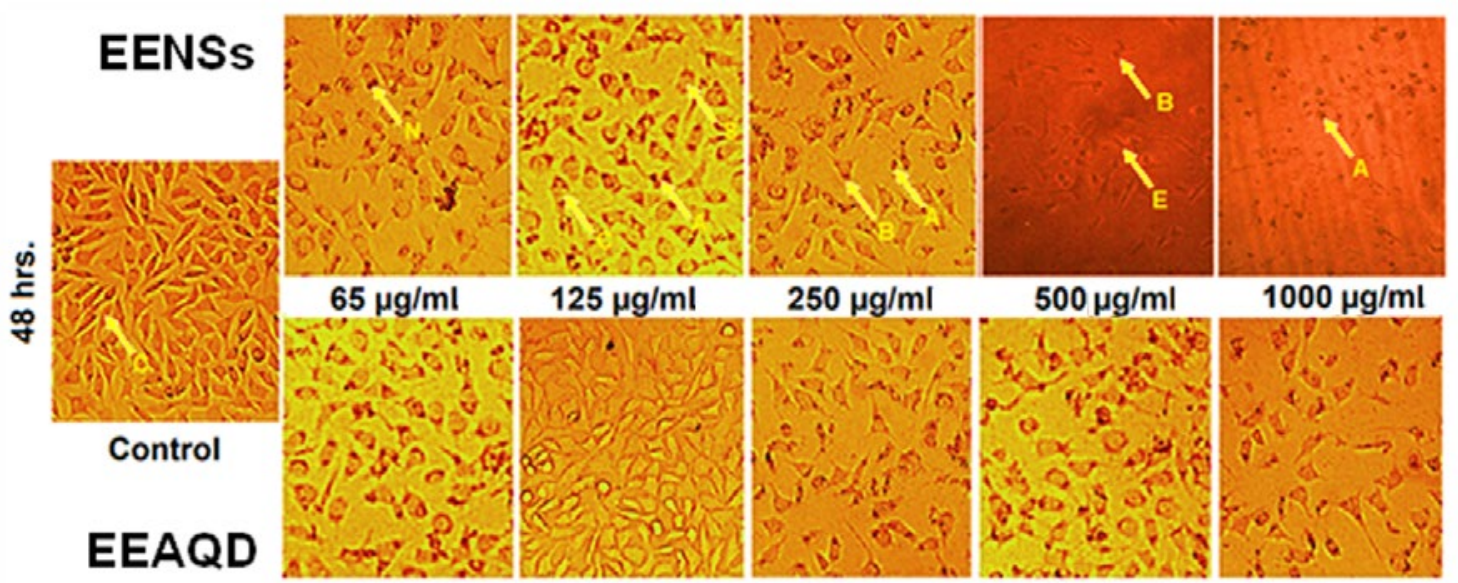

Fig. 6: Photomicrographs of morphological and growth inhibitory changes of MCF-7 cells induced by EENS and EEAQD Photomicrographs showing morphological and growth inhibitory changes of MCF-7 cells following exposure to EENSs for 48 h (light microscopy; $\times 200$ ). *Alphabets indicate, A. apoptotic bodies, B. membrane blebbing, C. cell shrinkage, N. condensed nuclei and $\mathrm{S \& E}$. echinoid spikes 

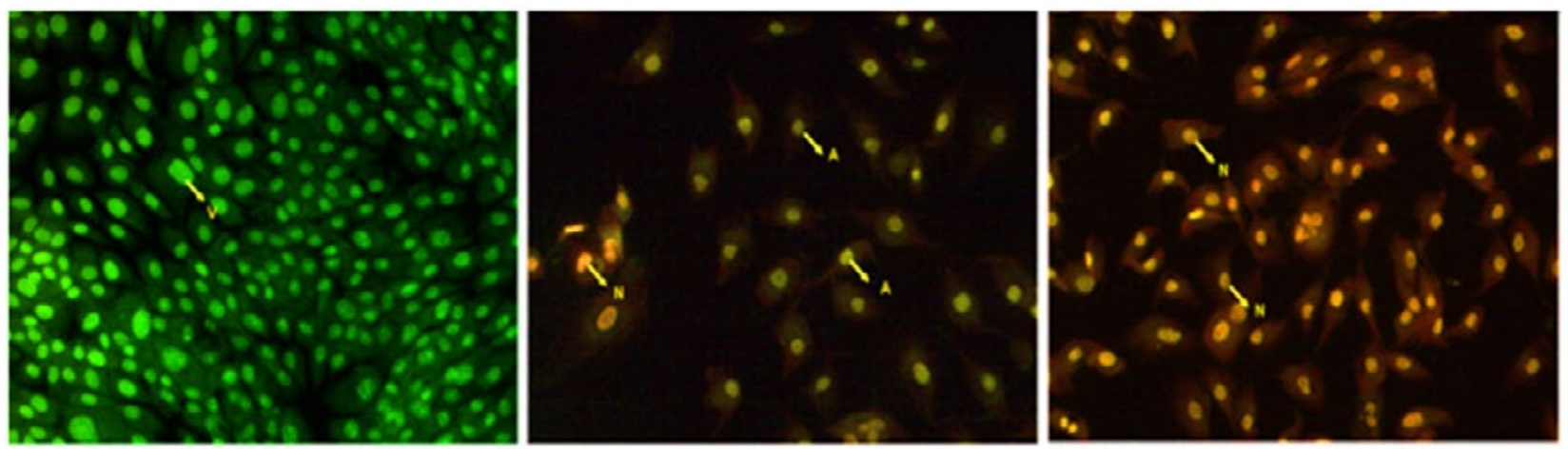

Fig. 7: Effect of EENS on MCF-7 cells

Apoptotic effect of etheinylestradiol nanosuspension (EENS) on MCF-7 cells. A) Untreated cell lines that are intact and with green nucleus B) Cells treated with $25 \mu \mathrm{g} / \mathrm{ml}$ of EEQAD C) Cells treated with $25 \mu \mathrm{g} / \mathrm{ml}$ of EENSs. N-necrotic cells, A- apoptic cells and $\mathrm{V}$ - viable cells
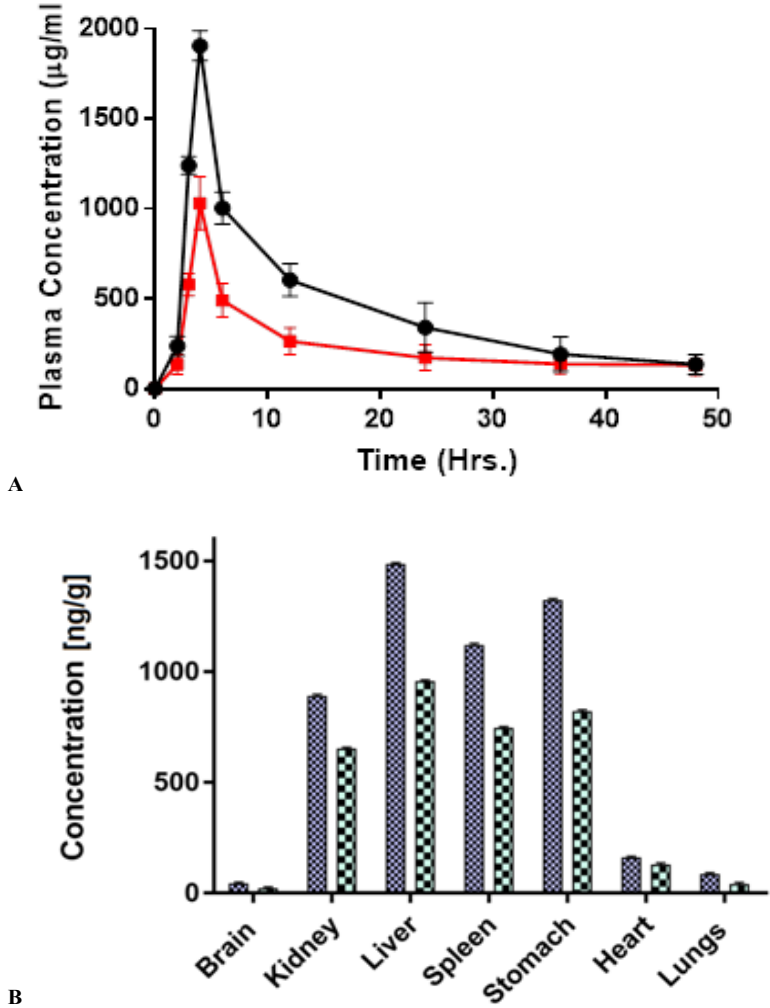

Fig. 8: Plasma concentration-time curve and biodistribution of EENS and EEAQD

Plasma concentration-time profiles and biodistribution of EENS and EEAQD after oral administration in rats (A) (-•-) EENSs, (一-) EEAQD; (B) (멱) EENS, (ㅈ) EEAQD. Each value represents the mean $\pm S D(n=3)$

EE to circulate in the body for a prolonged period, thus $\mathrm{T}_{\max }$ of EENS is higher than EEAQD. The relative bioavailability of EENS was found to be 1.7 as compared to EEAQD. The AUC is a vital PK parameter that explains the circulation and exposure time of the drug in bloodstreams ${ }^{[43]}$. The $\mathrm{AUC}_{0-\mathrm{t}}$ of EENS and EEAQD were $20777.18 \mathrm{ng} / \mathrm{ml} \times \mathrm{h}$ and $12290.12 \mathrm{ng} / \mathrm{ml} \times \mathrm{h}$, respectively. These increase in AUC indicated that oral absorption of EE in rats was enhanced notably in the
TABLE 1: PHARMACOKINETIC PARAMETERS OF EEAQD AND LYOPHILIZED EENS IN SPRAGUE DAWLEY RATS

\begin{tabular}{lcc}
\hline $\begin{array}{l}\text { Pharmacokinetic } \\
\text { parameters }\end{array}$ & EEAQD & Lyophilized EENS \\
\hline $\mathrm{C}_{\max }(\mathrm{ng} / \mathrm{ml})$ & $946.34 \pm 1.23$ & $1837.30 \pm 1.65^{* *}$ \\
$\mathrm{~T}_{\max }(\mathrm{h})$ & $4.00 \pm 1.45$ & $6.00 \pm 1.47^{* *}$ \\
$\mathrm{t}_{1 / 2}(\mathrm{~h})$ & $20.75 \pm 1.36$ & $14.10 \pm 1.33^{* *}$ \\
$M R T(\mathrm{~h})$ & $29.95 \pm 2.01$ & $20.35 \pm 2.01^{* *}$ \\
$A U C_{0 . \mathrm{t}}(\mathrm{ng} / \mathrm{ml} \times \mathrm{h})$ & $12290.12 \pm 4.25$ & $20777.17 \pm 3.14^{* *}$ \\
$A U C_{0 . \infty}(\mathrm{ng} / \mathrm{ml} \times \mathrm{h})$ & $15187.72 \pm 4.56$ & $22950.52 \pm 3.45^{* *}$ \\
$\mathrm{VD}(\mathrm{ml})$ & $0.01 \pm 2.42$ & $0.001 \pm 2.33^{* *}$ \\
$\mathrm{Cl}\left(\mathrm{ml} \mathrm{h} \mathrm{h}^{-1}\right)$ & $1.97 \times 10^{-5} \pm 2.55$ & $6.02 \times 10^{-5} \pm 2.65^{* *}$ \\
$\mathrm{KE}\left(\mathrm{h}^{-1}\right)$ & $0.03 \pm 2.45$ & $0.05 \pm 2.45^{* *}$ \\
$\mathrm{~F}_{\text {rel }}$ & - & $1.70 \pm 1.05$ \\
** $^{* *}<0.01$, compared to the corresponding parameters of EEAQD. \\
Results were expressed as the mean $\pm \mathrm{SD}(\mathrm{n}=3)$
\end{tabular}

lyophilized NS form. Thus oral bioavailability of EE was improved by decreasing particle size, enhanced membrane permeation and increased dissolution rate. As a stabilizer moreover, soya lecithin has a thick coat on the surface of EENS which played a vital role in bioavailability enhancement. It is an amphiphilic surfactant, that enhanced EE penetration ability and thus promoted rapid permeation of the EE nanoparticles through the intestinal epithelium and finally into the systemic circulation ${ }^{[33]}$.

After oral administration, the biodistribution study of EENS and EEAQD showed higher levels of EE in spleen, liver, stomach and kidney. Fig. 8B revealed the maximum concentration of EE in liver, spleen, stomach, and kidney were $1485.71 \pm 5.56,1122.43 \pm 4.88$, $1323.63 \pm 5.62$ and $891.16 \pm 5.33 \mathrm{ng} / \mathrm{g}$, respectively for EENS $48 \mathrm{~h}$ after oral administration. However, the EE concentrations from EEAQD in spleen, liver, stomach, and kidney were $745.62 \pm 3.78,956.89 \pm 4.56$, $821.23 \pm 5.02$ and $652.35 \pm 3.78 \mathrm{ng} / \mathrm{g}$, respectively. These 
lower levels could be attributed to faster elimination of EE due to higher particle size as compared to EENS. The higher uptake of EE in spleen, liver, and stomach is may be due to enhanced lymphatic uptake. The concentration of EE from EENS in the brain was $43.56 \pm 4.05 \mathrm{ng} / \mathrm{g}$ and from EEAQD was $22.46 \pm$ $4.35 \mathrm{ng} / \mathrm{g}$, respectively. The concentration of EE in lungs and heart were $86.82 \pm 3.02$ and $160.48 \pm 3.56 \mathrm{ng} / \mathrm{g}$ for EENS, while for EEAQD it was $42.65 \pm 4.33$ and $130.56 \pm 3.98 \mathrm{ng} / \mathrm{g}$, respectively. Thus, biodistribution studies indicated that the accumulation of EE from EENS in the spleen, liver, stomach, and kidneys in a larger amount as compared to the brain, lungs, and heart $^{[44]}$.

The six-month stability data for EENS and liquid EENS is presented in Table 2. NS stored at RT showed an increased particle size from 220 to 316 $\mathrm{nm}$ over 6 mo. Storage under refrigerated condition showed a nominal increase from 220 to $275 \mathrm{~nm}$ indicating better stability. NS stored at $40 \pm 2^{\circ} / 75 \pm 5 \%$ RH showed an increased particle size from 220 to $315 \mathrm{~nm}$. These observations indicated that temperature influenced aggregation of EE nanoparticles and hence it was higher at RT and above compared to refrigerator temperatures. Significant aggregation was more likely to occur in liquid EENS compared to lyophilized EENS at all storage conditions. Refrigerated conditions do not have a significant effect on average particle size, whereas at RT and $40 \pm 2^{\circ}$ there was a significant effect. Thus it can be concluded that at higher temperatures particle aggregation takes place, which might lead to the increased size of particles and thus makes them less stable. Probably Ostwald ripening could be the second reason resulting from fluctuations at RT. The results obtained from the chemical stability of formulation upon storage at different conditions are also presented in Table 2. Results suggested no significant change in EE content of liquid EENS and lyophilized EENS when stored at different storage conditions indicating that both the liquid and lyophilized NS are chemically stable at these storage conditions. Noteworthy, for physical stability of liquid EENS, lyophilization and storage at refrigerated conditions are recommended ${ }^{[45]}$.

The principal objective of this study was to develop lyophilized NS of EE to enhance its bioavailability, in vitro apoptosis and cytotoxicity against breast cancer MCF-7 cells using a top-down technique of HPH. Optimized NS was highly stable with improved dissolution rates, in vitro cytotoxicity, and bioavailability. The particle size distribution pattern of EENS showed an average particle size of $220 \pm 0.37$ $\mathrm{nm}$ with a zeta potential of $-19.3 \pm 6.73 \mathrm{mV}$. The surface morphological features of the lyophilized formulation presented porous slightly elongated needle-shaped particles whereas in liquid EENS particles were spherical with a layer of stabilizer coat. The crystalline form of EE was preserved in NS form and dissolution and release rate of EE from EENS was increased significantly, due to reduced particle size and increased surface area. In vitro cytotoxicity study of NS indicated a significant inhibitory effect of EE against MCF-7 cells at a very low dose. Apoptosis studies indicated that EENS-treated cells at a concentration of $12.5 \mu \mathrm{g} / \mathrm{ml}$ showed necrosis of cells followed by the death of cells inducing apoptosis. The plasma $\mathrm{C}_{\max }, \mathrm{T}_{\max }$, and $\mathrm{AUC}$ total of EENS in rats were significantly higher than those in EEAQD. The relative bioavailability of EENSs was enhanced by more than 2 fold. Biodistribution study suggested that a higher concentration of EE was found in the liver, spleen and kidney. The lyophilized NS was found to be stable when stored at refrigeration condition. Thus, EENS could be a promising concept in clinical application for cancer as well as contraceptive agents with enhanced bioavailability and stability. Thus, overall it can be concluded that optimized lyophilized NS of EE has enhanced the inhibitory effect on MCF-7 breast cancer cells with improved bioavailability and stability. These characteristics indicate the potential

\section{TABLE 2: STABILITY DATA OF LYOPHILIZED EENSS AND EENSs FOR SIX-MONTH STABILITY STUDY}

\begin{tabular}{|c|c|c|c|c|c|c|c|c|c|}
\hline \multirow[t]{2}{*}{ Formulation } & \multirow{2}{*}{$\begin{array}{c}\text { Storage } \\
\text { temperature }\end{array}$} & \multirow{2}{*}{$\begin{array}{l}\text { Initial } \\
\text { particle } \\
\text { size }\end{array}$} & \multicolumn{3}{|c|}{$\begin{array}{l}\text { Particle size } \\
\text { after }\end{array}$} & \multirow{2}{*}{$\begin{array}{l}\text { Initial drug } \\
\text { content }\end{array}$} & \multicolumn{3}{|c|}{$\begin{array}{l}\text { Drug content } \\
\text { after }\end{array}$} \\
\hline & & & $2 \mathrm{mo}$ & $4 \mathrm{mo}$ & $6 \mathrm{mo}$ & & $2 \mathrm{mo}$ & $4 \mathrm{mo}$ & $6 \mathrm{mo}$ \\
\hline \multirow[t]{3}{*}{$\begin{array}{l}\text { Lyophilized } \\
\text { EENS }\end{array}$} & $\begin{array}{l}4^{\circ} \\
\mathrm{RT}\end{array}$ & $220.4 \pm 10.3$ & $\begin{array}{l}230.5 \pm 6.8 \\
256.5 \pm 9.1\end{array}$ & $\begin{array}{l}255.8 \pm 8.2 \\
293.5 \pm 4.6\end{array}$ & $\begin{array}{l}275.9 \pm 4.6 \\
316.2 \pm 4.7\end{array}$ & \multirow[t]{2}{*}{$92.23 \pm 0.45$} & $\begin{array}{l}91.56 \pm 0.89 \\
90.56 \pm 0.56\end{array}$ & $\begin{array}{l}91.02 \pm 0.81 \\
89.02 \pm 0.62\end{array}$ & $\begin{array}{l}90.59 \pm 0.87 \\
88.63 \pm 0.74\end{array}$ \\
\hline & $40 \pm 2^{\circ}$ & & $260.4 \pm 8.1$ & $286.9 \pm 5.6$ & $315.4 \pm 5.6$ & & $90.88 \pm 0.96$ & $89.45 \pm 0.89$ & $88.03 \pm 0.97$ \\
\hline & $4^{\circ}$ & & $212.5 \pm 9.1$ & $225.8 \pm 4.6$ & $238.9 \pm 7.5$ & & $95.20 \pm 0.58$ & $94.65 \pm 0.65$ & $93.33 \pm 0.66$ \\
\hline \multirow[t]{2}{*}{ Liquid EENS } & RT & $209.4 \pm 10.3$ & $268.9 \pm 7.7$ & $308.9 \pm 7.1$ & $334.8 \pm 8.8$ & \multirow{2}{*}{$96.48 \pm 0.66$} & $93.25 \pm 0.47$ & $91.41 \pm 0.48$ & $89.63 \pm 0.41$ \\
\hline & $40 \pm 2^{\circ}$ & & $270.4 \pm 8.1$ & $299.2 \pm 5.5$ & $322.9 \pm 5.6$ & & $93.33 \pm 0.33$ & $92.00 \pm 0.54$ & $90.23 \pm 0.38$ \\
\hline
\end{tabular}


clinical application of NS of EE to treat breast cancer in addition to the already approved use as an oral contraceptive agent.

\section{Acknowledgments:}

The authors are grateful to Dr. Babasaheb Ambedkar Research and Training Institute (BARTI), Pune for providing funds to carry out the research work smoothly. Authors wish to acknowledge Dr. H. N. More, Principal of Bharati Vidyapeeth College of Pharmacy Kolhapur for providing necessary facilities to conduct research projects timely and smoothly.

\section{Conflict of interest:}

The authors report no conflicts of interest.

\section{Financial support and sponsorship:}

Nil.

\section{REFERENCES}

1. Evans G, Sutton EL. Oral contraception. Med Clin North Am 2015;99:479-503.

2. Williams CL, Stancel GM. Estrogens and progestins. In: Gilman AG, Goodman LS, Rall TW, Murad F, editors. The Pharmacological basis of therapeutics. New York: McGraw Hill; 1990. p. 1420-1.

3. Speroff L. Which oral contraceptive pill should be prescribed? In: Donna S, Haseltine PF, editors. Contraception. Berlin, Germany: Springer Science \& Business Media; 2012. p. 112.

4. Pellegrini A, Massidda B, Mascia V, Ionta MT, Lippi MG, Muggiano A, et al. Ethinyl estradiol and medroxyprogesterone treatment in advanced breast cancer: a pilot study. Cancer Treat Rep 1981;65(1-2):135-6.

5. Sueta A, Hayashi M, Fukugawa Y, Shimizu H, Ibusuki MY, Yamamoto Y, et al. Successful ethinylestradiol therapy for a metastatic breast cancer patient with heavily pre-treated with endocrine therapies. Int Cancer Conf J 2016;5(3):126-30.

6. Herjan JT, Bennink C, Verhoeven C, Thijssen J. The use of high-dose estrogens for the treatment of breast cancer. Maturitas 2017;95:11-23.

7. Iwase H, Yamamoto Y, Yamamoto-Ibusuki M, Murakami KI, Okumura Y, Tomita S, et al. Ethinylestradiol is beneficial for postmenopausal patients with heavily pre-treated metastatic breast cancer after prior aromatase inhibitor treatment: a prospective study. Br J Cancer 2013;109:153742.

8. Agrawal A, Robertson JFR, Cheung KL. Efficacy and tolerability of high dose "ethinylestradiol" in post-menopausal advanced breast cancer patients heavily pre-treated with endocrine agents. World J Surg Oncol 2006;4:44.

9. Izumi K, Kadono Y, Shima T, Konaka H, Mizokami A, Koh $\mathrm{E}$, et al. Ethinylestradiol improves prostate-specific antigen levels in pretreated castration-resistant prostate cancer patients. Anticancer Res 2010;30(12):5201-5.

10. Bennink HC, Visser M. Estetrol (E4), the forgotten fetal steroid. Proceedings of the 9th European Congress of Endocrinology; 2007 April 28- May 02; Budapest, Hungary: European Society of Endocrinology; 2007.

11. Isabela PV, Daniel JS, Eduardo CC, Garcia JS, Trevisan MG. Development, characterization, and stability studies of ethinyl estradiol solid dispersion. J Therm Anal Calorim 2015;120(1):573-81.

12. Sattar A, Chen D, Jiang L, Pan Y, Tao Y, Huang L, et al. Preparation, characterization, and pharmacokinetics of cyadox nanosuspension. Sci Rep 2017;7:1-9.

13. Garg M, Mishra D, Agashe H, Jain NK. Ethinylestradiolloaded ultraflexible liposomes: pharmacokinetics and pharmacodynamics. J Pharm Pharmacol 2006;58:459-68.

14. Zhang $\mathrm{T}$, Murowchick J, Youan BB. Optimization of formulation variables affecting spray-dried oily core nanocapsules by response surface methodology. J Pharm Sci 2011;100(3):103144.

15. Merisko-Liversidge EM, Liversidge GG. Drug nanoparticles: formulating poorly water-soluble compounds. Toxicol Pathol 2008;36(1):43-8.

16. Sharma P, Denny WA, Garg S. Effect of wet milling process on the solid-state of indomethacin and simvastatin. Int J Pharm 2009;380(1-2):40-8.

17. Lobenberg R, Amidon GL. Modern bioavailability, bioequivalence and biopharmaceutics classification system. New scientific approaches to international regulatory standards. Eur J Pharm Biopharm 2000;50(1):3-12.

18. Lai F, Sinico C, Ennas G, Marongiu F, Marongiu G, Fadda AM. Diclofenac nanosuspensions: influence of preparation procedure and crystal form on drug dissolution behavior. Int J Pharm 2009;373(1-2):124-32.

19. Patel VR, Agrawal YK. Nanosuspension: An approach to enhance the solubility of drugs. J Adv Pharm Technol Res 2011;2(2):81-7.

20. Kesisoglou F, Panmai S, Wu Y. Nano sizing - Oral formulation development and biopharmaceutical evaluation. Adv Drug Deliv Rev 2007;59(7):631-44.

21. Gol D, Thakkar S, Misra M. Nanocrystal-based drug delivery system of risperidone: lyophilization and characterization. Drug Dev Ind Pharm 2018;44(9):1458-66.

22. Gao L, Liu G, Ma J, Wang X, Zhou L, Li X. Drug nanocrystals: In vivo performances. J Control Release 2012;160(3):418-30.

23. Gao Y, Li Z, Sun M, Guo C, Yu A, Xi Y, et al. Preparation and characterization of intravenously injectable curcumin nanosuspension. Drug Deliv 2011;18(2):131-42.

24. Hao L, Wang X, Zhang D, Xu Q, Song S, Wang F. Studies on the preparation, characterization, and pharmacokinetics of Amoitone B nanocrystals. Int J Pharm 2012;433(1-2):157-64.

25. Huang Q, Yu H, Ru Q. Bioavailability and delivery of nutraceuticals using nanotechnology. J Food Sci 2010;75:50-7.

26. Müller RH, Peters K. Nanosuspensions for the formulation of poorly soluble drugs: I. Preparation by a size-reduction technique. Int J Pharm 1998;160:229-37.

27. Maskarinec SA, Hannig J, Lee RC, Lee KY. Direct observation of poloxamer 188 insertions into lipid monolayers. Biophys J 2002;82(3):1453-9.

28. Trotta M, Gallarate M, Pattarino F, Morel S. Emulsions containing partially water-miscible solvents for the preparation of drug nanosuspensions. J Control Release 2001;76(1-2):11928.

29. Sun W, Mao S, Shi Y, Li LC, Fang L. Nanonization of itraconazole by high-pressure homogenization: stabilizer optimization and effect of particle size on oral absorption. J Pharm Sci 2011;100(8):3365-73.

30. Vadlamudi HC, Yalavarthi PR, Venkata BR, Thanniru J, 
Vandana KR, Sundaresan CR. Potential of microemulsified entacapone drug delivery systems in the management of acute Parkinson's disease. J Acute Dis 2016;5(4):315-25.

31. Dora CP, Singh SK, Kumar S, Datusalia AK, Deep A. Development and characterization of nanoparticles of glibenclamide by the solvent displacement method. Acta Pol Pharm 2010;67(3):283-90.

32. Yue PF, Zheng Q, Wu B, Hu PY, Wu ZF, Yan MJ. Application of Plackett-Burman Design and Box-Behnken Design to achieve process optimization for Geniposide submicron emulsion. Dis Sci Technol 2012;33:213-22.

33. Kalvakuntla S, Deshpande M, Attari Z, Kunnatur K. Preparation and characterization of nanosuspension of aprepitant by $\mathrm{H} 96$ process B. Adv Pharm Bull 2016;6(1):83-90.

34. Rabelo L, Monteiro N, Serquiz R, Santos P, Oliveira R, Oliveira A, et al. A lactose-binding lectin from the marine sponge cinachyrella apion (cal) induces cell death in human cervical adenocarcinoma cells. Mar Drugs 2012;10:727-43.

35. Zhang H, Chen W, Zhao Z, Dong Q, Yin L, Zhou J, et al. Lyophilized nanosuspensions for oral bioavailability improvement of insoluble drugs: preparation, characterization, and pharmacokinetic studies. J Pharm Innov 2017;12(3):27180.

36. He J, Han Y, Xu G, Yin L, Neubi NM, Zhou J, et al. Preparation and evaluation of celecoxib nanosuspensions for bioavailability enhancement. RSC Adv 2017;7:13053-64.

37. Borhade V, Pathak S, Sharma S, Patravale V. Formulation and characterization of atovaquone nanosuspension for improved oral delivery in the treatment of malaria. Nanomedicine 2014;9(5):649-66.

38. Pandya VM, Patel JK, Patel DJ. Formulation and optimization of nanosuspensions for enhancing simvastatin dissolution using Central Composite Design. Dissolut Technol 2011:18(3):40-5.

39. Abdelbary AA, Al-mahallawi AM, Abdelrahim ME, Ali A. Preparation, optimization, and in vitro simulated inhalation delivery of carvedilol nanoparticles loaded on a coarse carrier intended for pulmonary administration. Int $\mathrm{J}$ Nanomedicine 2015:10(1):6339-53.

40. Engblom P, Pulkkinen JO, Rantanen V, Hirvonen H, Kulmala $\mathrm{J}$, Grènman $\mathrm{R}$, et al. Effects of paclitaxel with or without cremophor EL on cellular clonogenic survival and apoptosis. Eur J Cancer 1999;(35):284-8.

41. Ghosh I, Michniak-Kohn B. Influence of Critical Parameters of Nanosuspension Formulation on the Permeability of a Poorly Soluble Drug through the Skin-A Case Study. AAPS Pharm Sci Tech 2013;14(3):1108-17.

42. Wong J, Brugger A, Khare A, Chaubal M, Papadopoulos P, Rabinow B, et al. Suspensions for intravenous (IV) injection: a review of development, preclinical and clinical aspects. Adv Drug Deliv Rev 2008;(60):939-54.

43. Feng FF, Zhang DR, Tian KL, Lou HY, Qi XL, Wang YC, et al. Growth inhibition and induction of apoptosis in MCF-7 breast cancer cells by oridonin nanosuspension. Drug Deliv 2011;18(4):265-71.

44. Bagad M, Khan ZA. Poly(n-butylcyanoacrylate) nanoparticles for oral delivery of quercetin: preparation, characterization, and pharmacokinetics and biodistribution studies in Wistar rats. Int J Nanomedicine 2015;10:3921-35.

45. Vuppalapati L, Cherukuri S, Neeli V, Yeragamreddy RP, Kesavan BR. Application of Central Composite Design in the optimization of valsartan nanosuspension to enhance its solubility and stability. Curr Drug Deliv 2016;13:143-57. 